\title{
Short communication: Performance of Holstein calves fed high-solid milk with or without nucleotide
}

\author{
Y. Abbaslou, ${ }^{1}$ E. Mahjoubi, ${ }^{1}$ F. Ahmadi, ${ }^{2}$ M. R. Farokhzad, ${ }^{3}$ D. Zahmatkesh, ${ }^{1}$ M. Hossein Yazdi, ${ }^{4}$ \\ and $\mathrm{H}$. Beiranvand ${ }^{3 *}$ \\ ${ }^{1}$ Department of Animal Science, University of Zanjan, Zanjan, 45371-38791, Iran \\ ${ }^{2}$ Division of Food Biosciences, College of Medical Life Sciences, Konkuk University, Chungju, Chungbuk 380-701, South Korea \\ ${ }^{3}$ Chaltasian Agri.-Animal Production Complex, Varamin, Tehran, 33751-13111, Iran \\ ${ }^{4}$ Department of Animal Science, Arak University, Arak, 38156, Iran
}

\section{ABSTRACT}

Our initial hypothesis was that the exogenous supply of nucleotides to neonatal calves would improve the development and functionality of gastrointestinal tissue, thereby enhancing their capacity to efficiently digest and utilize the nutrients in high-solids milk. Twenty 3 -d-old male Holstein calves $(37.9 \pm 2.24 \mathrm{~kg}$ of body weight) were distributed randomly to 1 of 2 treatments ( 1 calf per pen; 10 pens per treatment) without or with added nucleotides to their daily milk. Dry milk powder was added to pasteurized milk and offered as $4 \mathrm{~L} / \mathrm{d}$ from d 3 to $15,6 \mathrm{~L} / \mathrm{d}$ from d 16 to 49 (at 0900 and $1600 \mathrm{~h}$ ), and $2 \mathrm{~L} / \mathrm{d}$ in morning feeding from $\mathrm{d} 50$ to 55. High-solids milk (fat $=4.47 \%$, protein $=4.64 \%$, lactose $=8.13 \%$, and total solids $=17.7 \%$ ) was made through the addition of milk powder into whole milk and supplemented without or with $2 \mathrm{~g} / \mathrm{d}$ of a commercially available nucleotide product, and then fed until weaning. Nucleotide supplementation had no effect on preweaning growth rate, but tended to increase postweaning daily weight gain (d 56-75). Unexpectedly, nucleotide supplementation tended to increase fecal score within the $10 \mathrm{~d}$ of calf life; thereafter (until weaning), no difference was detected in fecal consistency. Nucleotide supplementation tended to increase and increased pre- and postweaning dry matter intake, respectively. Efficiency of feed utilization (kilogram of weight gain per kilogram of dry matter intake) was not influenced with treatment. The net gain (d 1-70) of withers height and hip height tended to be greater in nucleotide-fed calves. Overall, addition of nucleotides to the high-solids milk had marginal effects on preweaning performance and tended to increase fecal scores (looser feces) in the initial phase of life; however, it increased starter feed intake and growth rate after weaning. A

Received May 28, 2020.

Accepted July 21, 2020.

*Corresponding author: hamedbeiran669@gmail.com longer-feeding experiment is recommended to elucidate the potential effects of nucleotide supplementation in high-solids milk on calf performance.

Key words: growth performance, nucleotide, calf, starter intake, postweaning

\section{Short Communication}

As components of coenzymes, nucleotides from nucleic acids (DNA and RNA) play crucial roles in several physiological reactions such as energy storage and transfer reactions (Voet and Voet, 1995; Yu, 2002). Nucleotides also contribute to optimizing the function of fast-dividing tissues, stimulating growth, and boosting immune function (Uauy, 1994; Cameron et al., 2001). The de novo synthesis of nucleotides is an energy-requiring process (Carver and Walker, 1995); therefore, the contribution to the nucleotide pools, via their exogenous supply during the early stage of animal life with the elevated energy requirement, might leave more available energy to support the optimum growth and health of the living organism. Moreover, intestinal mucosa is incapable of de novo synthesis of nucleotides (Sanderson and He, 1994); therefore, the exogenous supply of nucleotides might potentially benefit the development of gastrointestinal tissue in young animals, whereby promoting their growth and development.

Our recent experiment found that although nucleotide addition ( $1 \mathrm{~g} / \mathrm{d}$; Ascogen, Chemoforma, Switzerland) in whole milk had slight effects on preweaning feed intake and growth rate, it decreased abnormal fecal scores during the first month of calf life, and increased postweaning feed intake and calf final BW (unpublished data: Y. Abbaslou, D. Zahmatkesh, E. Mahjoubi, Department of Animal Science, University of Zanjan, Zanjan, Iran; M. Hossein Yazdi, Department of Animal Science, Arak University, Arak, Iran; H. Beiranvand, Chaltasian Agri.-Animal Production Complex, Varamin, Tehran; M. Gorjidooz, Department of Clinical Science, Faculty of Veterinary Medicine, Islamic Azad 
University, Garmsar Branch, Garmsar, Iran). Kehoe et al. (2008) reported that although nucleotide supplementation in calf milk replacer had no effect on growth rate and immunity, it improved intestinal morphology and decreased days with diarrhea in neonatal calves. The positive effect of exogenous nucleotides in neonates is likely related to the progressively increased demand of the rapidly developing or challenged intestinal tissues to nucleotides because the nucleotide demand of theses tissues exceeds the amount synthesized within the body (Uauy et al., 1990; Kehoe et al., 2008). Bueno et al. (1994) also showed that the slow and incomplete recovery of the intestinal tissues after diarrhea was accelerated after nucleotides were exogenously supplemented in the diet of weanling rats. This positive effect was also accompanied by the increased microvillus surface area and improvement of mitochondrial function. Contrary to these findings, the extra supply of nucleotides at 10 and $20 \%$ in milk replacer had no benefits in calf growth and health (Hill et al., 2016). This suggests that the high concentrations of nucleotides might not benefit calf performance.

Increased nutrient intake through milk or milk replacer in intensive calf feeding programs will usually benefit growth rate (with low deposition of fat), gain:feed ratio, and immune function (Brown et al., 2005; Raeth-Knight et al., 2009; Kertz and Loften, 2013). Although limited supportive information exists, an intensive calf feeding regimen is also linked to the phenotypic expression that potentially benefits the first-lactation performance (Soberon et al., 2012). However, to our knowledge, there is no information about the response of neonatal calves to nucleotide supplementation in high-solids milk. We hypothesized that the exogenous supply of nucleotides to newborn calves would contribute to the improvement of intestinal health; therefore, the increased supply of nutrients through high-solids milk feeding would enhance nutrient absorption and utilization, and thus improve calf performance and health.

Animal procedures were conducted in conformance with the Iranian Council of Animal Care (1995). A detailed description of calf management is previously reported (Azad-Shahraki et al., 2019). In brief, 20 newborn male Holstein calves were enrolled for the experiment that was conducted in a commercial dairy farm (Chaltasian Agri.-Animal Production Complex; Varamin, Tehran, Iran). Calves received $6 \mathrm{~L}$ of colostrum within the first $12 \mathrm{~h}$ of life. The colostrum quality was checked based on its IgG concentration using a Volac colostrometer (Royston, UK). If the IgG concentration exceeded the cut-off point of $50 \mathrm{mg} / \mathrm{mL}$, it was fed to calves. Beginning at $3 \mathrm{~d}$ old $(37.9 \pm 2.24 \mathrm{~kg}$ of $\mathrm{BW}$; mean $\pm \mathrm{SD}$ ), calves were housed in individual pens $(1.5 \mathrm{~m} \times 2.5 \mathrm{~m})$ and randomly assigned to 1 of 2 treatments: without or with nucleotide supplementation $(2 \mathrm{~g} / \mathrm{d})$ in high-solids milk until weaning. The pens were located inside a roofed area with open sides, enabling access to natural light. A purified nucleotide product derived from Saccharomyces cerevisiae yeast (Ascogen) was added daily to the morning milk, which was reconstituted with dry milk powder to increase the total solids to $17.7 \%$. Calves received their daily milk through a step-up/step-down milk-feeding regimen as 4 $\mathrm{L}$ of milk/d from d 3 to $15,6 \mathrm{~L} / \mathrm{d}$ from d 16 to 49 (at 0900 and $1600 \mathrm{~h}$ ), and $2 \mathrm{~L} / \mathrm{d}$ in morning feeding from d 50 to weaning (d 55). The experiment continued until d 75. The milk samples were analyzed weekly using CombiScope FTIR 600 Dairy analyzer (Delta Instruments, Netherlands) for fat $(4.47 \pm 0.15 \%)$, protein $(4.64 \pm 0.11 \%)$, lactose $(8.13 \pm 0.77 \%)$, total solids $(17.7 \pm 0.81 \%)$, total unsaturated fatty acid $(29.8 \pm$ $0.96 \%)$, and total saturated fatty acids $(55.5 \pm 1.87 \%)$. Fresh water was accessible through a nipple. From d 1 to 75 of experiment, calves had free-choice access to a starter diet (Table 1), which was formulated based on NRC (2001) recommendations. The starter diet was composed of a concentrate component in meal form and wheat straw that was chopped to a geometric particle size of $2.6 \mathrm{~mm}$. Starter intake was recorded daily, and calves were weighed every $10 \mathrm{~d}$. Withers height and hip height were measured on $\mathrm{d} 1,30,60$ and 70 of the experiment. Calf fecal consistency was scored individually on a daily basis during the milk-feeding period using a 5-point scale of Heinrichs et al. (2003).

Table 1. Description of the starter diet

\begin{tabular}{lc}
\hline Items & Values, $\%$ of DM \\
\hline Ingredients & \\
Wheat straw & 10.0 \\
Corn grain, meal & 50.2 \\
Wheat bran & 4.50 \\
Soybean meal, $45 \% \mathrm{CP}$ & 28.8 \\
Sodium bicarbonate & 0.90 \\
Calcium carbonate & 1.80 \\
Salt & 0.90 \\
Bentonite & 1.40 \\
Vitamin and mineral mix ${ }^{1}$ & 1.50 \\
Nutrient composition & \\
DM, $\%$ as fed & 91.3 \\
CP, $\%$ of DM & 18.1 \\
NDF, $\%$ of DM & 23.5 \\
Total fat, \% of DM & 2.93 \\
ME, ${ }^{2}$ Mcal/kg of DM & 2.52 \\
NE ${ }_{\mathrm{G}}{ }^{2}$ Mcal/kg of DM & 1.44 \\
\hline
\end{tabular}

${ }^{1}$ Contained, per $\mathrm{kg}$ of premix: 250,000 IU of vitamin A, 50,000 IU of vitamin $\mathrm{D}, 1,500 \mathrm{IU}$ of vitamin $\mathrm{E}, 2.25 \mathrm{~g}$ of $\mathrm{Mn}, 120 \mathrm{~g}$ of $\mathrm{Ca}, 7.7 \mathrm{~g}$ of $\mathrm{Zn}, 20 \mathrm{~g}$ of P, $20.5 \mathrm{~g}$ of Mg, $186 \mathrm{~g}$ of Na, $1.25 \mathrm{~g}$ of Fe, $3 \mathrm{~g}$ of S, $14 \mathrm{mg}$ of $\mathrm{Co}, 1.25 \mathrm{~g}$ of $\mathrm{Cu}, 56 \mathrm{mg}$ of I, and $10 \mathrm{mg}$ of Se.

${ }^{2}$ Calculated using NRC (2001) equations. 
Prior to data analysis, normality of the continuous data was checked using UNIVARIATE Proc in SAS (SAS Institute, Cary, NC). If any data were not normally distributed, logarithmic or square-root transformations were made to meet expectations of normality. The data were analyzed as a completely randomized design using MIXED Proc. Calf was the experimental unit. Data of starter intake, daily gain, and feed efficiency were analyzed separately with repeated measures. Autoregressive type 1 resulted in the smallest Akaike information criterion and was selected. Birth weight was included in the model as a covariate. Fecal score data were analyzed as described before (Fouladgar et al., 2016). In brief, the daily record of fecal scores scaling from 1 to 5 were binary-coded as 0 if the score was 1 or 2 (healthy) and 1 if the score was 3 or greater (diarrhea). For the adjustment of repeated measures on the same calf, calf served as a random variable in the model. Autoregressive type 1 was used in the model for fecal score analysis. The difference between treatments was identified using GENMOD Proc with a binomial distribution and logit link function. The difference between treatments for frequency of abnormal fecal days (fecal score $\geq 3$ ) was identified using GENMOD Proc with a Poisson distribution (Kargar and Kanani, 2019). The data on the average amounts of antibiotics or fluids given per occurrence (in gram or milliliter per treatment) were analyzed as a completely randomized design, using MIXED Proc of SAS. Significance level was noted at $P<0.05$.

None of the calves died or were removed from the experiment. Performance of calves fed high-solids milk without or with nucleotide supplementation is presented in Table 2. Total DMI tended to be greater $(P$ $=0.07$ ) and was greater in nucleotide-fed calves during pre- and postweaning periods, respectively. Treatment

Table 2. Performance of calves offered high-solids milk without or with $2 \mathrm{~g}$ of nucleotides/d

\begin{tabular}{|c|c|c|c|c|}
\hline \multirow[b]{2}{*}{ Item $^{1}$} & \multicolumn{2}{|c|}{ Treatment } & \multirow[b]{2}{*}{ SEM } & \multirow[b]{2}{*}{$P$-value } \\
\hline & $\begin{array}{c}\text { Control } \\
(\mathrm{n}=10)\end{array}$ & $\begin{array}{l}\text { Nucleotide } \\
(\mathrm{n}=10)\end{array}$ & & \\
\hline \multicolumn{5}{|l|}{$\overline{\mathrm{BW}}, \mathrm{kg}$} \\
\hline Initial, d 3 & 38.4 & 37.3 & 0.72 & 0.32 \\
\hline Weaning, d 55 & 72.5 & 72.6 & 1.69 & 0.97 \\
\hline Final, d 75 & 90.7 & 94.5 & 2.35 & 0.27 \\
\hline Weight gain, d 3 to 75 & 52.4 & 57.2 & 2.35 & 0.16 \\
\hline \multicolumn{5}{|l|}{ Daily gain, $\mathrm{kg} / \mathrm{d}$} \\
\hline Preweaning, d 3 to 55 & 0.61 & 0.68 & 0.03 & 0.17 \\
\hline Postweaning, d 56 to 75 & 0.98 & 1.26 & 0.09 & 0.06 \\
\hline Total, d 3 to 75 & 0.70 & 0.81 & 0.04 & 0.05 \\
\hline \multicolumn{5}{|l|}{ Total DMI, ${ }^{2} \mathrm{~kg} / \mathrm{d}$} \\
\hline Preweaning, d 3 to 55 & 1.05 & 1.17 & 0.05 & 0.07 \\
\hline Milk DMI & 0.76 & 0.78 & 0.01 & 0.22 \\
\hline Starter DMI & 0.29 & 0.39 & 0.48 & 0.11 \\
\hline Postweaning, d 56 to 75 & 2.53 & 3.24 & 0.16 & $<0.01$ \\
\hline Total, d 3 to 75 & 1.42 & 1.69 & 0.07 & 0.01 \\
\hline \multicolumn{5}{|l|}{ Feed efficiency ${ }^{3}$} \\
\hline Preweaning, d 3 to 55 & 0.59 & 0.58 & 0.02 & 0.67 \\
\hline Postweaning, d 56 to 75 & 0.38 & 0.39 & 0.03 & 0.78 \\
\hline Total, d 3 to 75 & 0.54 & 0.53 & 0.02 & 0.61 \\
\hline \multicolumn{5}{|l|}{ Withers height, $\mathrm{cm}$} \\
\hline Initial, d 1 & 76.5 & 75.0 & 0.78 & 0.19 \\
\hline d 30 & 80.9 & 79.4 & 0.61 & 0.10 \\
\hline d 60 & 87.4 & 86.9 & 0.64 & 0.55 \\
\hline d 70 & 90.1 & 90.2 & 0.55 & 0.95 \\
\hline Difference, d 1 - d 70 & 13.6 & 15.2 & 0.59 & 0.08 \\
\hline \multicolumn{5}{|l|}{ Hip height, cm } \\
\hline Initial, d 1 & 79.6 & 77.9 & 0.78 & 0.15 \\
\hline d 30 & 84.4 & 82.8 & 0.60 & 0.03 \\
\hline d 60 & 90.2 & 90.3 & 0.64 & 0.35 \\
\hline d 70 & 93.8 & 93.7 & 0.59 & 0.91 \\
\hline Difference, d $1-$ d 70 & 14.3 & 15.9 & 0.58 & 0.07 \\
\hline
\end{tabular}

${ }^{1}$ Transformations were made on data of preweaning starter and milk DMI, in addition to withers height (d 60) and hip height (d 30 and 60) to improve their normality before statistical analysis. The nontransformed data are presented herein.

${ }^{2}$ Milk DM + starter DM.

${ }^{3}$ Feed efficiency $=$ kilogram of weight gain per kilogram of total DMI. 
had no effect on weaning and final BW; however, postweaning daily gain (from d 56-75) tended to be greater $(P=0.06)$ in nucleotide-fed calves, which is possibly a function of their greater starter intake. However, feed efficiency was not affected by treatment. The net gain (calculated as d 1-70) of withers height $(P=0.08)$ and hip height $(P=0.07)$ tended to be greater in nucleotidefed calves. Recently, Abbaslou et al. (unpublished data: Y. Abbaslou, D. Zahmatkesh, E. Mahjoubi, Department of Animal Science, University of Zanjan, Zanjan, Iran; M. Hossein Yazdi, Department of Animal Science, Arak University, Arak, Iran; H. Beiranvand, Chaltasian Agri-Animal Production Complex, Varamin, Tehran; M. Gorjidooz, Department of Clinical Science, Faculty of Veterinary Medicine, Islamic Azad University, Garmsar Branch, Garmsar, Iran) added nucleotide (Ascogen) to whole milk $(0,0.5$, or $1 \mathrm{~g} / \mathrm{d})$ and observed that although preweaning DMI was not affected with nucleotide addition, it increased linearly after weaning, which was reflected in a linear increase in final BW (d 75). In agreement with the observation that nucleotide supplementation had no effect on preweaning growth rate, Kehoe et al. (2008) also found that the purified nucleotides or those from an extract of $S$. cerevisiae had minor effects on growth rate of neonatal calves. In contrast, Hill et al. (2016) reported that calf weight gain and feed efficiency declined linearly from 0 to 4 wk and 0 to 8 wk as contents of a $S$. cerevisiae-based nucleotide product (NuPro; Alltech Inc., Nicholasville, KY) increased from 0 to $20 \%$ in the milk replacer $(27 \%$ $\mathrm{CP}, 17 \%$ fat), which was explained by the poor digestion of the nucleotide product. Similarly, Clifford and Story (1976) found no improvement in growth rate of rats fed diets with or without nucleotides. The possible explanations for these inconsistencies are the differences in nucleotide products, in addition to the level and method of supplementation.

Treatment effects on fecal consistency and medical treatments, including antibiotic use and fluid therapy, are presented in Table 3. Contrary to our expectation, fecal consistency declined $(P=0.07)$ in nucleotide-fed calves during the first $10 \mathrm{~d}$ of life; afterward, no effect was observed in calf fecal consistency. However, number of days with an abnormal fecal score was not different among treatments. Nucleotide supplementation had no effect on the amount of antibiotic use and intravenous fluid therapy. Our previous investigation found that the addition of the same nucleotide product to whole milk $(0,0.5$, or $1 \mathrm{~g} / \mathrm{d})$ linearly decreased the number of days with an abnormal fecal score during the first month of calf life (unpublished data: Y. Abbaslou, D. Zahmatkesh, E. Mahjoubi, Department of Animal Sci-

Table 3. Fecal consistency and medical treatments in calves offered high-solids milk without or with $2 \mathrm{~g}$ of nucleotides/d

\begin{tabular}{|c|c|c|c|c|}
\hline \multirow[b]{2}{*}{ Item $^{2}$} & \multicolumn{2}{|c|}{ Treatment $^{1}$} & \multirow[b]{2}{*}{ SEM } & \multirow[b]{2}{*}{$P$-value } \\
\hline & $\begin{array}{c}\text { Control } \\
(\mathrm{n}=10)\end{array}$ & $\begin{array}{l}\text { Nucleotide } \\
(\mathrm{n}=10)\end{array}$ & & \\
\hline \multicolumn{5}{|l|}{ Fecal score ${ }^{3}$} \\
\hline d 1 to 10 & 2.26 & 2.36 & 0.03 & 0.07 \\
\hline d 11 to 20 & 1.92 & 1.96 & 0.02 & 0.54 \\
\hline d 21 to 55 & 1.58 & 1.62 & 0.02 & 0.56 \\
\hline \multicolumn{5}{|l|}{ Abnormal fecal days (fecal score $\geq 3$ ) } \\
\hline d 1 to 10 & 2.70 & 3.70 & 0.31 & 0.20 \\
\hline d 11 to 20 & 0.50 & 0.70 & 0.15 & 0.56 \\
\hline d 21 to 55 & 0.20 & 0.10 & 0.08 & 0.57 \\
\hline \multicolumn{5}{|l|}{ Antibiotic treatment } \\
\hline Enrofloxacin, ${ }^{4} \mathrm{~g} /$ calf & $4.1(7)$ & $5.0(8)$ & 0.77 & 0.43 \\
\hline Neomycin, g/calf & $1.5(10)$ & $1.3(10)$ & 0.19 & 0.47 \\
\hline \multicolumn{5}{|l|}{ Intravenous fluid therapy } \\
\hline Hypertonic saline solution,${ }^{5} \mathrm{~mL} /$ calf & $100(7)$ & $125(8)$ & 21.4 & 0.41 \\
\hline Hypertonic dextrose solution, ${ }^{6} \mathrm{~mL} /$ calf & $71.4(7)$ & $62.5(8)$ & 10.9 & 0.59 \\
\hline
\end{tabular}

${ }^{1}$ Values in parentheses indicate the number of calves in each treatment that received antibiotics or intravenous fluids. The corresponding $P$-values are related to the average amount of antibiotics or fluids given to each calf.

${ }^{2}$ Transformation was made on the data of medical treatment to improve their normality before statistical analysis. The nontransformed data are presented herein.

${ }^{3}$ Daily feces of individual calf were scored as: $1=$ normal; $2=$ soft to loose; $3=$ loose to watery; $4=$ watery, mucous, slightly bloody; 5 = watery, mucous, and bloody.

${ }^{4}$ Enrovet 10\% (Enrofloxacin, Bayer Aflak, Pharmaceutical Co., Lorestan, Iran).

${ }^{5} 7.2 \mathrm{~g}$ of sodium chloride per $100 \mathrm{~mL}$ of solution (osmolarity $=2.46 \mathrm{mOsmol} / \mathrm{mL}$ ).

${ }^{6} 50 \mathrm{~g}$ of dextrose per $100 \mathrm{~mL}$ of solution (osmolarity $=2.77 \mathrm{mOsmol} / \mathrm{mL}$ ). 
ence, University of Zanjan, Zanjan, Iran; M. Hossein Yazdi, Department of Animal Science, Arak University, Arak, Iran; H. Beiranvand, Chaltasian Agri.-Animal Production Complex, Varamin, Tehran; M. Gorjidooz, Department of Clinical Science, Faculty of Veterinary Medicine, Islamic Azad University, Garmsar Branch, Garmsar, Iran). Based on this observation, the initial hypothesis of the current experiment was that the additional supply of nucleotides during the first days of calf life, which is a critical and challenging period, benefits calf intestinal health, and thus calf growth and performance. In support of our observations on calf fecal score, Kehoe et al. (2008) added a purified nucleotide (derived from $S$. cerevisiae) to calf milk replacer and found no improvements in intestinal morphology or functionality, but the loss of fecal water and calf dehydration were increased in nucleotide-fed calves. However, Kentler et al. (2012) observed that nucleotide supplementation (Ascogen, $2 \mathrm{~g} / \mathrm{d}$ ) in milk replacer had no effect on diarrhea incidence in calves from birth to 3 wk of age. Exogenous supply of nucleotides (0, 0.5, or $1.0 \%$ ) also had a negligible effect on fecal score and incidence of diarrhea in piglets from d 1 to weaning (Jiao et al., 2019). However, Hill et al. (2016) observed that the number of days with abnormal fecal scores decreased linearly from 0 to $4 \mathrm{wk}$ as nucleotides increased from 0 to $20 \%$ in milk replacer. The authors explained the reduction in fecal score by the poor digestion of the of nucleotides at high inclusion rates that possibly increased fecal output of solids.

In conclusion, contrary to our initial hypothesis that nucleotide supplementation might improve the gastrointestinal health and functionality of neonatal calves, addition of nucleotides in high-solids milk tended to decrease fecal consistency within the first $10 \mathrm{~d}$ of calf life and had marginal effects on preweaning growth rate and feed intake. However, it improved starter intake and weight gain after weaning. Indicators of rumen fermentation and development in young calves supplemented with nucleotides would possibly provide helpful information with regard to the improvement in starter intake. This necessitates additional experiments to elucidate such effects. Further experiments of longer durations with a larger number of calves are needed to clarify the efficacy of exogenous nucleotide supplementation in young calves when offered high-solids milk.

\section{ACKNOWLEDGMENTS}

Chaltasian Agri.-Animal Production Complex (Varamin, Iran) is acknowledged for kindly providing the farm facilities that enabled the implementation of this study. Shahryar Saffari is also appreciated for his collaboration throughout the experiment. The authors have not stated any conflicts of interest.

\section{REFERENCES}

Azad-Shahraki, M., M. Khani, F. Ahmadi, M. Ariana, and H. Beiranvand. 2019. Palmitic acid supplementation does not improve performance of pre-ruminant calves. Anim. Feed Sci. Technol. 255:114220. https://doi.org/10.1016/j.anifeedsci.2019.114220.

Brown, E. G., M. J. VandeHaar, K. M. Daniels, J. S. Liesman, L. T. Chapin, D. H. Keisler, and M. W. Nielsen. 2005. Effect of increasing energy and protein intake on body growth and carcass composition of heifer calves. J. Dairy Sci. 88:585-594. https://doi.org/10 .3168/jds.S0022-0302(05)72722-3.

Bueno, J., M. Torres, A. Almendros, R. Carmona, M. C. Nunez, A. Rios, and A. Gil . 1994. Effect of dietary nucleotides on small intestinal repair after diarrhea. Histological and ultrastructural changes. Gut 35:926-933. https://doi.org/10.1136/gut.35.7.926.

Cameron, B. F., C. W. Wong, G. N. Hinch, D. Sigh, J. V. Nolan, and I. G. Colditz. 2001. Effects of nucleotides on the immune function of early-weaned piglets. Pages 66-68 in Digestive Physiology of Pigs. J. E. Lindberg, B. Ogle, ed. CABI Publishing, New York, NY.

Carver, J. D., and W. Allan Walker. 1995. The role of nucleotides in human nutrition. J. Nutr. Biochem. 6:58-72. https://doi.org/10 .1016/0955-2863(94)00019-I.

Clifford, A. J., and D. L. Story. 1976. Levels of purines in foods and their metabolic effects in rats. J. Nutr. 106:435-442. https://doi .org/10.1093/jn/106.3.435.

Fouladgar, S., A. F. Shahraki, G. R. Ghalamkari, M. Khani, F. Ahmadi, and P. S. Erickson. 2016. Performance of Holstein calves fed whole milk with or without kefir. J. Dairy Sci. 99:8081-8089. https://doi.org/10.3168/jds.2016-10921.

Heinrichs, A. J., C. M. Jones, L. R. VanRoekel, and M. A. Fowler. 2003. Calf track: A system of dairy calf workforce management, training, and evaluation and health evaluation. J. Dairy Sci. 86(Suppl. 1):115.

Hill, T. M., F. X. Suarez-Mena, H. G. Bateman II, J. M. Aldrich, and R. L. Schlotterbeck. 2016. Effect of nucleotides in milk replacers on growth and health of male dairy calves. Prof. Anim. Sci. 32:214-219. https://doi.org/10.15232/pas.2015-01492.

Iranian Council of Animal Care. 1995. Guide to the Care and Use of Experimental Animals vol. 1. Isfahan University of Technology, Isfahan, Iran.

Jiao, Y., S. D. Upadhaya, and I. H. Kim. 2019. Effects of nucleotide supplementation to corn-soybean meal-based diet on growth performance, fecal microflora, and blood profiles of sows and performance of suckling piglets. Can. J. Anim. Sci. 99:754-763. https:// doi.org/10.1139/cjas-2018-0222.

Kargar, S., and M. Kanani. 2019. Substituting corn silage with reconstituted forage or nonforage fiber sources in the starter feed diets of Holstein calves: Effects on intake, meal pattern, sorting, and health. J. Dairy Sci. 102:7168-7178. https://doi.org/10.3168/jds .2019-16455.

Kehoe, S. I., A. J. Heinrichs, C. R. Baumrucker, and D. L. Greger. 2008. Effects of nucleotide supplementation in milk replacer on small intestinal absorptive capacity in dairy calves. J. Dairy Sci. 91:2759-2770. https://doi.org/10.3168/jds.2007-0751.

Kentler, C., C. Guzman, and T. Frankel. 2012. Supplementation of hand-reared calves with nucleotides from birth to 3 weeks of age and effects on health and immunity. Page 286 in Proc. 5th Australasian Dairy Science Symposium, Melbourne, Australia.

Kertz, A. F., and J. R. Loften. 2013. A historical perspective of specific milk-replacer feeding programs in the United States and effects on eventual performance of Holstein dairy calves. Prof. Anim. Sci. 29:321-332. https://doi.org/10.15232/S1080-7446(15)30245-X.

National Research Council. 2001. Nutrient Requirements of Dairy Cattle, 7th edition. Academic Press, Washington, DC. 
Raeth-Knight, M., H. Chester-Jones, S. Hayes, J. Linn, R. Larson, D. Ziegler, B. Ziegler, and N. Broadwater. 2009. Impact of conventional or intensive milk replacer programs on Holstein heifer performance through six months of age and during first lactation. J. Dairy Sci. 92:799-809. https://doi.org/10.3168/jds.2008-1470.

Sanderson, I. R., and Y. He. 1994. Nucleotide uptake and metabolism by intestinal epithelial cells. J. Nutr. 124(Suppl. 1):131S-137S. https://doi.org/10.1093/jn/124.suppl_1.131S.

Soberon, F., E. Raffrenato, R. W. Everett, and M. E. Van Amburgh. 2012. Preweaning milk replacer intake and effects on long-term productivity of dairy calves. J. Dairy Sci. 95:783-793. https://doi .org/10.3168/jds.2011-4391.

Uauy, R. 1994. Nonimmune system responses to dietary nucleotides. J. Nutr. 124(Suppl. 1):157S-159S. https://doi.org/10.1093/jn/124 .suppl_1.157S.
Uauy, R., G. Stringel, R. Thomas, and R. Quan. 1990. Effect of dietary nucleosides on growth and maturation of the developing gut in the rat. J. Pediatr. Gastroenterol. Nutr. 10:497-503. https://doi.org/ 10.1097/00005176-199005000-00014.

Voet, D., and J. G. Voet. 1995. Nucleotide Metabolism. Pages 795-797 in Biochemistry, 2nd ed. N. Rose, ed. John Wiley and Sons Inc., New York, NY.

Yu, V. Y. H. 2002. Scientific rationale and benefits of nucleotide supplementation of infant formula. J. Paediatr. Child Health 38:543549. https://doi.org/10.1046/j.1440-1754.2002.00056.x. 